\title{
Pelaksanaan Antenatal Care Berhubungan dengan Anemia pada Kehamilan Trimester III di Puskesmas Sedayu I Yogyakarta
}

\author{
Fatimah $^{1}$, Susi Ernawati \\ 1,2, Sekolah Tinggi IImu Kesehatan Alma Ata Yogyakarta \\ Jalan Ringroad Barat Daya No 1 Tamantirto, Kasihan, Bantul, Yogyakarta
}

\begin{abstract}
Abstrak
Anemia merupakan salah satu masalah di Indonesia yang penting untuk dikaji, terutama pada ibu hamil. Penelitian ini merupakan penelitian kuantitatif dengan rancangan explanatory research. Populasi sebanyak 44 ibu hamil trimester III yang diambil secara total sampling. Variabel independen pelaksanaan antenatal care oleh bidan dan variabel dependen anemia dalam kehamilan trimester III di puskesmas Sedayu I Yogyakarta. Pengambilan data menggunakan kuesioner. Uji analisis menggunakan chi-square. Hasil penelitian didapatkan pelayanan antenatal care sebanyak 33 (75\%) dalam kategori baik, sebanyak 32 (72,7\%) responden tidak mengalami anemia, dan ada hubungan yang signifikan antara pelayanan antenatal care dengan anemia pada kehamilan trimester III dengan p-value=0,004. Kesimpulan penelitian bahwa ada hubungan antara pelayanan antenatal care oleh bidan dengan anemia dalam kehamilan trimester III. Saran perlunya mempertahankan dan lebih meningkatkan pelayanan antenatal care bidan dalam meningkatkan derajat kesehatan ibu hamil terutama anemia pada kehamilan.
\end{abstract}

Kata Kunci: pelayanan antenatal care, anemia

\section{The Implementation of Antenatal Care Related with Anemia in Third Trimester of Pregnancy at Puskesmas Sedayu I Yogyakarta}

\begin{abstract}
Anemia is one of the problems in Indonesia that important to examine, especially for pregnant women. This research used quantitative with explanatory design. Population were 44 pregnant women in $3^{\text {rd }}$ trimester selected by the total sampling technique. The independent variable were implementation of the antenatal care by midwives and dependent variable is anemia in $3^{\text {rd }}$ trimester of pregnancy at Puskesmas Sedayu I Yogyakarta. Data was collected using questionnaire. The analysis used was chi-square. The results of study showed that there was 33 (75\%) of antenatal care in good category, with no anemia were $32(72.7 \%)$ respondents, and there was a significant relationship between antenatal care and anemia in the third trimester of pregnancy with $p$-value $=0.004$. In conclusion, there was a significant relationship between antenatal care and anemia in the third trimester of pregnancy. Suggestions were needed to maintain and improve the care of midwives in antenatal care to improve the health of pregnant women, especially anemia in pregnancy.
\end{abstract}

Keywords: antenatal care services, anemia

Info Artikel:

Artikel dikirim pada 17 Mei 2015

Artikel diterima pada 17 Mei 2015 


\section{PENDAHULUAN}

Anemia merupakan masalah yang masih terjadi pada wanita khususnya ibu hamil. Prevalensi anemia secara umum terjadi pada 56 juta ibu hamil yang tersebar di seluruh dunia dengan pembagian sekitar 7 juta di Eropa dan Amerika dan sisanya yaitu 49 juta terjadi di negara maju, berkembang dan negara miskin di Asia dan Afrika(1).

Angka anemia kehamilan di Indonesia menunjukan nilai yang cukup tinggi. Hoo Swie Tjiong dalam Manuaba menemukan angka anemia kehamilan $3,8 \%$ pada trimester I, $13,6 \%$ trimester II, dan $24,8 \%$ pada trimester III, sedangkan menurut Saifudin menyebutkan angka anemia secara nasional untuk ibu hamil mencapai angka $63,5 \%(2)(3)$.

Sebagian besar penyebab anemia di Indonesia adalah kekurangan zat besi yang berasal dari makanan yang dimakan setiap hari dan diperlukan untuk pembentukan hemoglobin sehingga disebut anemia kekurangan besi. Anemia yang disebabkan oleh kekurangan zat besi dapat menyebabkan risiko bayi berat lahir rendah, prematuritas, cacat bawaan dan perdarahan pada waktu melahirkan(4).

Prevalensi terjadinya anemia pada wanita hamil di Indonesia cukup tinggi yaitu berkisar $20 \%$ $80 \%$, tetapi pada umumnya banyak penelitian yang menunjukan prevalensi anemia pada wanita hamil yang lebih besar dari $50 \%$. Sehingga dapat dikatakan 5 dari 10 wanita hamil di Indonesia menderita Anemia. World Health Organization (WHO) melaporkan bahwa prevalensi anemia pada kehamilan secara global $55 \%$ dimana secara bermakna tinggi pada trimester III(5).

Penanganan anemia dengan pemberian suplemen tablet zat besi $(\mathrm{Fe})$ yang merupakan suatu cara yang paling efektif untuk meningkatkan kadar zat besi $(\mathrm{Fe})$ dalam jangka waktu yang pendek pada ibu hamil. Pelayanan bidan dalam mencegah terjadinya anemia melalui pemeriksaan antenatal care (ANC) kepada setiap ibu hamil. Peran bidan mendukung peningkatan konsumsi tablet zat besi. Tetapi, Kenyataannya pemberian tablet besi belum efektif menurunkan prevalensi anemia. Alasan utama kurang efektif adalah rendahnya kepatuhan ibu hamil dalam mengkonsumsi tablet besi. Sehingga peran bidan mendapatkan tantangan yang lebih besar untuk meningkatkan kepercayaan ibu hamil dalam mengkonsumsi tablet zat besi, bidan mampu memberikan dukungan dan mengurangi efek samping yang dapat terjadi pada ibu hamil jika mengkonsumsi zat besi. Tujuan penelitian untuk mengetahui apakah ada hubungan antara pelaksanaan ANC oleh bidan dengan kejadian anemia dalam kehamilan.

\section{BAHAN DAN METODE}

Jenis penelitian ini merupakan penelitian kuantitatif dengan rancangan penelitian explanatory research. Penelitian dilakukan di Puskesmas Sedayu I Bantul Yogyakarta pada bulan September 2015. Populasi penelitian adalah seluruh ibu hamil trimester III di Puskesmas Sedayu I dengan cara pengambilan sampel menggunakan sampel populasi sebanyak 44 ibu hamil trimester III. Penelitian menggunakan kuesioner hasil adopsi dari penelitian Heryanti yang telah dilakukan uji validitas dan reliabilitas di Puskesmas Pajangan kepada 20 responden(6). Variabel bebas penelitian ini adalah pelayanan antenatal care oleh bidan, sedangkan variabel bebas adalah anemia dalam kehamilan trimester III.

\section{HASIL DAN BAHASAN}

\section{Analisis Univariat}

Responden penelitian merupakan ibu hamil Trimester III di Puskesmas Sedayu I yang dilihat dari beberapa karakteristik antara lain: umur, pendidikan, pekerjaan dan jarak kehamilan.

Tabel 1. Distribusi Frekuensi Umur Ibu Hamil Trimester III di Puskesmas Sedayu I

\begin{tabular}{lcc}
\hline \multicolumn{1}{c}{ Umur } & $\mathbf{f}$ & $\%$ \\
\hline $21-34$ th & 34 & 97,7 \\
$>35$ th & 1 & 2,3 \\
Jumlah & 44 & 100 \\
\hline
\end{tabular}

Sumber: Data Primer Tahun 2015

Bedasarkan Tabel 1 menunjukkan bahwa sebagian besar responden berumur 21-34 tahun yaitu sebanyak 34 orang $(97,7 \%)$. Departemen Kesehatan RI, kelompok umur berisiko yaitu $<20$ tahun atau $>35$ tahun. Usia lbu waktu melahirkan kurang dari 20 tahun atau lebih dari 35 tahun telah terbukti merupakan penyebab tinggi morbiditas bahkan mortalitas ibu maupun anak. Hal tersebut dapat meningkat jika ibu mengalami anemia(7).

Anemia dapat meningkat pada ibu hamil yang mempunyai usia $<20$ tahun karena pada usia muda tersebut membutuhkan zat besi lebih banyak selain untuk keperluan pertumbuhan diri 
sendiri juga janin yang dikandungnya. Hal ini juga meningkat pada kehamilan dengan usia ibu hamil >35 tahun karena usia ini usia yang kurang baik untuk reproduksi. Kehamilan ibu di atas 35 tahun akan mengalami problem kesehatan seperti hipertensi, diabetes melitus, anemia, dan penyakit-penyakit kronis lainnya.

Tabel 2. Distribusi Frekuensi Pendidikan Ibu Hamil Trimester III di Puskesmas Sedayu I

\begin{tabular}{lcc}
\hline Pendidikan & f & \% \\
\hline SD & 2 & 4,5 \\
SMP & 9 & 20,5 \\
SMA & 26 & 59,1 \\
PT & 7 & 15,9 \\
Jumlah & 44 & 100 \\
\hline
\end{tabular}

Sumber: Data Primer Tahun 2015

Berdasarkan Tabel 2 tingkat pendidikan diketahui bahwa persentase yang tertinggi adalah responden dengan tingkat pendidikan menengah atas atau SMA sebanyak 26 orang $(59,1 \%)$. Sedangkan jumlah responden yang tamat SD sebanyak 2 orang $(4,5 \%)$.

Berdasarkan Tabel 2 tingkat pendidikan ibu hamil trimester III di Puskesmas Sedayu I diketahui bahwa prosentase yang tertinggi adalah responden dengan tingkat pendidikan menengah atas atau SMA sebanyak 26 orang $(59,1 \%)$. Sedangkan jumlah responden yang tamat SD sebanyak 2 orang $(4,5 \%)$.

Wanita yang berpendidikan rendah atau tidak berpendidikan lebih banyak mempunyai anak lebih daripada wanita yang berpendidikan lebih tinggi. Wanita yang berpendidikan redah lebih sulit mencerna informasi dari tenaga kesehatan tentang dampak negatip banyak anak yang kurang berkualitas.

Tabel 3. Distribusi Frekuensi Pekerjaan Ibu Hamil Trimester III di Puskesmas Sedayu I

\begin{tabular}{lcc}
\hline \multicolumn{1}{c}{ Pekerjaan } & f & \% \\
\hline IRT & 29 & 65,9 \\
Swasta & 13 & 29,5 \\
Guru & 2 & 4,5 \\
Jumlah & 44 & 100 \\
\hline
\end{tabular}

Sumber: Data Primer Tahun 2015

Berdasarkan Tabel 3 pekerjaan responden diketahui bahwa paling banyak dari jumlah keseluruhan yaitu 44 orang ibu hamil trimester III adalah Ibu Rumah Tangga sebanyak 29 orang $(65,9 \%)$. Sedangkan bekerja swasta sebanyak 13 orang $(29,5 \%)$ dan sebagai guru 2 orang $(4,5 \%)$.

Berdasarkan Tabel 3 pekerjaan responden diketahui bahwa paling banyak dari jumlah keseluruhan yaitu 44 orang ibu hamil trimester III adalah Ibu Rumah Tangga sebanyak 29 orang $(65,9 \%)$. Sedangkan bekerja swasta sebanyak 13 orang $(29,5 \%)$ dan sebagai guru 2 orang $(4,5 \%)$.

Seorang ibu hamil yang tidak bekerja atau sebagai ibu rumah tangga minim mendapatkan informasi, termasuk informasi tentang kesehatan karena interaksi dengan orang lain kurang. Sedangkan ibu hamil yang bekerja lebih banyak mendapatkan informasi karena lebih banyak berinteraksi dengan orang lain.

Tabel 4. Distribusi Frekuensi Jarak Kehamilan Ibu Hamil Trimester III di Puskesmas Sedayu I

\begin{tabular}{lcc}
\hline Jarak Kehamilan & f & \% \\
\hline $1-3$ th & 23 & 52,3 \\
$4-5$ th & 13 & 29,5 \\
$>6$ th & 8 & 18,2 \\
Jumlah & 44 & 100 \\
\hline
\end{tabular}

Sumber: Data Primer Tahun 2015

Berdasarkan Tabel 4 jarak kehamilan diketahui bahwa sebagian besar responden mempunyai jarak kehamilan atau jarak dengan anak yang terkecil pada usia 0-3 tahun yaitu sebanyak 23 orang $(52,3 \%)$.

Berdasarkan Tabel 4 jarak kehamilan diketahui bahwa sebagian besar responden mempunyai jarak kehamilan atau jarak dengan anak yang terkecil pada usia 0-3 tahun yaitu sebanyak 23 orang $(52,3 \%)$. Salah satu penyebab yang dapat meningkatkan terjadinya anemia pada wanita adalah jarak kelahiran yang pendek. Hal ini disebabkan karena adanya kekurangan nutrisi yang merupakan mekanisme biologis dari pemulihan faktor hormonal dari kehamilan sebelumnya(8). Sedangkan menurut data Badan Koordinasi Keluarga Berencana Nasional (BKKBN) jarak persalinan yang baik adalah minimal 24 bulan atau 2 tahun karena hormone kehamilan sebelumnya sudah kembali dan anak sebelumnya sudah mendapatkan ASI cukup. 
Tabel 5. Distribusi Pelayanan ANC oleh Bidan di Puskesmas Sedayu I

\begin{tabular}{lcc}
\hline \multicolumn{1}{c}{ Pelayanan } & f & $\%$ \\
\hline Baik & 33 & 75,0 \\
Kurang Baik & 11 & 25,0 \\
Jumlah & 44 & 100 \\
\hline
\end{tabular}

Sumber: Data Primer Tahun 2015

Berdasarkan Tabel 5 data hasil penelitian diketahui bahwa sebagian besar responden menyatakan pelayanan ANC oleh bidan di Sedayu I baik yaitu sebanyak 33 (75\%), sedangkan responden yang menyatakan kurang baik sebanyak $11(25 \%)$.

Penelitian ini sejalan dengan penelitian Wijayanti, T dkk tentang Analisis Pengaruh Penerapan Standart Pelayanan Kehamilan Terhadap Kunjungan Ibu Hamil Di Puskesmas Gemolong Sragen Tahun 2011. Hasil penelitian sebagian besar responden diberi pelayanan kebidanan sesuai standart, sebanyak 25 responden (64,1\%)(9).

Hasil penelitian ini juga sejalan dengan penelitian Wundashary tentang Analisis Mutu Pelayanan Antenatal Care Di Puskesmas Wonrely Kabupaten Maluku Barat Daya Provinsi Maluku Tahun 2012. Hasil penelitian diketahui mutu pelayanan antenatal banyak responden yang menyatakan cukup baik yakni 50 orang $(52,6 \%)$, sedangkan mutu pelayanan antenatal kurang maksimal adalah 45 orang $(47,4 \%)(10)$.

Tabel 6. Distribusi Kejadian Anemia pada Ibu Hamil Trimester III di Puskesmas Sedayu I

\begin{tabular}{lcc}
\hline \multicolumn{1}{c}{ Status Anemia } & f & \% \\
\hline Tidak Anemia & 32 & 72,7 \\
Anemia & 12 & 27,3 \\
Jumlah & 44 & 100 \\
\hline
\end{tabular}

Sumber: Data Primer Tahun 2015

Berdasarkan Tabel 6 hasil penelitian yang telah dilakukan dari status anemia terlihat responden yang tidak anemia sebanyak 32 orang $(72,7 \%)$, sedangkan yang anemia sebanyak 12 orang $(27,3 \%)$. Penyebab anemia pada kehamilan ada 2 faktor. Faktor pertama langsung status anemia pada kehamilan disebabkan oleh malnutrisi, kurang zat besi, malabsorpsi, dan penyakit kronis (TB, malaria, cacingan, dan lain-lain). Sedangkan faktor kedua tidak langsung antara lain dapat disebabkan oleh umur ibu waktu hamil, pengetahuan tentang anemia pada kehamilan, paritas, dan kualitas pelayanan kesehatan yang diberikan oleh bidan. Hal ini sejalan dengan penelitian Heryanti, tentang gambaran mutu pelayanan dan tingkat kepuasan ibu hamil trimester III oleh bidan dalam penanggulangan anemia di Puskesmas Pajangan Kabupaten Bantul tahun 2015(6).

Hasil penelitian pada responden yang tidak anemia sebanyak $80 \%$, sedangkan yang anemia sebanyak $20 \%$. Penelitian ini juga sejalan dengan penelitian yang dilakukan oleh Jaya, tentang Hubungan Tingkat Pengetahuan Mengkonsumsi Makanan yang Mengandung Fe dengan Kejadian Anemia Ibu Hamil Di Puskesmas Ngampilan Yogyakarta. Hasil penelitian didapatkan bahwa dari 30 responden diketahui sebanyak 8 responden $(26,7 \%)$ mengalami anemia, sedangkan 22 responden $(73,3 \%)$ tidak mengalami anemia(11).

\section{Analisis Bivariat}

Hasil hubungan pelayanaan ANC oleh bidan dengan kejadian anemia pada ibu hamil trimester III di puskesmas Sedayu I Bantul Yogyakarta.

Berdasarkan Tabel 7 hasil analisis hubungan pelayanan ANC oleh bidan dengan kejadian anemia pada ibu hamil trimester III diperoleh bahwa ada 5 $(15,2 \%)$ ibu yang mendapatkan pelayananan ANC baik yang tidak mengalami anemia. Sedangkan diantara ibu yang mendapatkan pelayanan ANC kurang baik, ada 7 (63,6\%) mengalami anemia.

Berdasarkan hasil uji chi-square didapatkan adanya nilai expected count ada $25 \%$, maka tidak dapat menggunakan memenuhi syarat untuk menggunakan chi-square pada nilai continuity

Tabel 7. Hubungan Pelayanaan ANC oleh Bidan Dengan Kejadian Anemia pada Ibu Hamil Trimester III

\begin{tabular}{|c|c|c|c|c|c|c|c|c|}
\hline \multirow{3}{*}{ Variabel ANC } & \multicolumn{4}{|c|}{ Kejadian Anemia } & \multirow{2}{*}{\multicolumn{2}{|c|}{ Total }} & \multirow{3}{*}{ OR-95\% } & \multirow{3}{*}{ p-value } \\
\hline & \multicolumn{2}{|c|}{ Tidak Anemia } & \multicolumn{2}{|c|}{ Anemia } & & & & \\
\hline & $\mathbf{n}$ & $\%$ & $\mathbf{n}$ & $\%$ & $\mathbf{n}$ & $\%$ & & \\
\hline Baik & 28 & 84,8 & 5 & 15,2 & 44 & 100 & 9,8 & 0,004 \\
\hline Kurang Baik & 4 & 36,4 & 7 & 63,6 & 44 & 100 & $2,0-46,3$ & \\
\hline
\end{tabular}


correction, tetapi dibaca fisher's exact testnya dengan hasil 0.004 yang artinya adanya hubungan pelayanan ANC bidan dengan kejadian anemia ibu hamil Trimester III di puskesmas Sedayu I Bantul Yogyakarta. Sedangkan hasil analisis nilai OR 9,800 , artinya ibu hamil yang mendapatkan ANC mempunyai peluang 9,8 kali tidak mengalami anemia pada kehamilannya.

Hasil penelitian ini sejalan dengan Vasra, E tentang Hubungan Pelayanan Antenatal dan Budaya Masyarakat dengan Perubahan Kadar Haemoglobin Ibu Hamil Sesudah Pemberian Tablet Besi di Puskesmas Cakupan Rendah dan Puskesmas Cakupan Tinggi. Hasil penelitian diketahui adanya hubungan pelayanan antenatal dengan Kadar Haemoglobin Ibu Hamil(12).

Penelitian ini sejalan dengan Hendrayani, tentang perilaku pemeriksaan antenatal sebagai faktor risiko anemia gizi ibu hamil di Puskesmas II Denpasar Selatan tahun 2012. Hasil penelitian kontak pertama ibu hamil dijumpai mayoritas $(53,5 \%)$ setelah trimester I dengan frekuensi pemeriksaan yang tidak memadai dan terbukti sebagai faktor risiko anemia $(\mathrm{OR}=23,29)(13)$.

Penelitian ini juga sejalan dengan Sistiarani, tentang faktor maternal dan kualitas pelayanan antenatal yang berisiko terhadap kejadian berat badan lahir rendah (BBLR) studi pada ibu yang periksa hamil ke tenaga kesehatan dan melahirkan di RSUD Banyumas tahun 2008. Pada responden dengan kejadian anemia yang mendapat pelayanan ANC baik $(13,2 \%)$ lebih kecil dibandingkan dengan responden yang mendapat pelayanan ANC kurang baik $(63,6)$. Hasil penelitian menunjukkan bahwa variabel yang berhubungan dengan kejadian BBLR adalah riwayat penyakit selama hamil yaitu anemia didapatkan nilai $\mathrm{p}=0,03(\mathrm{OR}=2,91 ; 1,09$ $8,2)$ dan kualitas pelayanan antenatal nilai $p=0,001$ $(\mathrm{OR}=5,85 ; 1,9-17,88)(14)$.

\section{SIMPULAN DAN SARAN}

Berdasarkan hasil penelitian yang dilakukan pada ibu hamil trimester III di Puskesmas Sedayu dapat disimpulkan bahwa karakteristik ibu hamil trimesteer III dari umur sebagian besar responden berumur 21-34 tahun yaitu sebanyak 34 orang $(97,7 \%)$. tingkat pendidikan SMA 26 orang $(59,1 \%)$, ibu rumah tangga sebanyak 29 orang $(65,9 \%)$, jarak kehamilan yaitu sebanyak 23 orang ( $52,3 \%$ ).
Pelayanan ANC oleh bidan kepada ibu hamil trimester III dalam kategori baik yaitu sebanyak 33 (75\%). Status anemia pada ibu hamil trimester III sebagian besar tidak mengalami anemia yaitu sebanyak 32 orang (72,7\%). Hubungan pelayaaan ANC oleh bidan dengan kejadian anemia pada ibu hamil trimester III dengan uji Fisher's 0,004 artinya adanya hubungan pelayanan ANC bidan dengan kejadian anemia ibu hamil Trimester III di puskesmas Sedayu I Bantul Yogyakarta.

Saran dalam penelitian ini adalah agar lebih memperhatikan kondisi ibu hamil terutama yang mengalami anemia, sehingga instansi kesehatan baik Rumah Sakit, Klinik Pratama, Rumah Bersalin, Puskesmas atau Praktik Mandiri Bidan lebih meningkatkan kualitas ANC yang komprehensif dan sesuai prosedur atau kebijakan pemerintah.

\section{RUJUKAN}

1. Milman N. Postpartum anemia II: prevention and treatment. Ann Hematol. 2013;91 (2):143-54.

2. Manuaba IBG. Gawat-Darurat Obstetri-Ginekologi dan Obstetri-Ginekologi Sosial Untuk Profesi Bidan. Jakarta: EGC; 2010.

3. Saifudin. Buku Acuan: Asuhan Persalinan Normal. Jakarta: EGC; 2005.

4. Waryono. Gizi Reproduksi. Yogyakarta: Pustaka Rihanna; 2010.

5. WHO. World Health Statistics [internet]. 2008 [cited 2015 Apr 13]. Available from: http: //www. who.int/whosis/whostat/Corrigenda_20080521.pdf

6. Heryanti N. Gambaran Mutu Pelayanan Dan Tingkat Kepuasan Ibu Hamil Trimester III Oleh Bidan Dalam Penanggulangan Anemia di Puskesmas Pajangan Kabupaten Bantul Tahun 2015. Yogyakarta: StiKes Alma Ata; 2015.

7. Depkes RI. Laporan Hasil Riset Kesehetan Dasar (Riskesdas) Indonesia 2007. Jakarta: Depkes Rl; 2008.

8. Darlina. Faktor-faktor yang Berhubungan dengan Kejadian Anemia Gizi pada Ibu Hamil. Bogor: Departemen Gizi Masyarakat dan Sumberdaya Keluarga, Fakultas Pertanian Institut Pertanian Bogor; 2008.

9. Wijayanti T, et al. Analisis Pengaruh Penerapan Standart Pelayanan Kehamilan Terhadap Kunjungan Ibu Hamil di Puskesmas Gemolong Sragen Tahun 2011. Akademi Kebidanan Estu Utomo Boyolali. Jurnal Kebidanan. 2013;5(2). 
10. Wundashary. Analisis Mutu Pelayanan Antenatal Care di Puskesmas Wonrely Kabupaten Maluku Barat Daya Provinsi Maluku Tahun 2012 [internet]. 2013 [cited 2015 Sept 23]. Available from: http://repository.unhas.ac.id/ bitstream/han dle/123456789/5821/JURNAL\%20 (WUNDASHARY\%20D\%20A\%20DEMNY). pdf?sequence $=1$

11. Jaya E. Hubungan Tingkat Pengetahuan Mengkonsumsi Makanan yang Mengandung Fe dengan Kejadian Anemia Ibu Hamil di Puskesmas Ngampilan Yogyakarta. Yogyakarta: StiKes Alma Ata; 2012.

12. Vasra E. Hubungan Pelayanan Antenatal dan Budaya Masyarakat dengan Perubahan Kadar Haemoglobin Ibu Hamil Sesudah Pemberian
Tablet Besi di Puskesmas Cakupan Rendah dan Puskesmas Cakupan Tinggi. FK UNPAD; 2012. 13. Hendrayani MD, Sawitri AAS, Karmaya M. Perilaku pemeriksaan antenatal sebagai faktor risiko anemia gizi ibu hamil di Puskesmas II Denpasar Selatan tahun 2012. Public Health and Preventive Medicine Archive. 2013;1(1).

14. Sistiarani C. Tentang Faktor Maternal dan Kualitas Pelayanan Antenatal yang Berisiko Terhadap Kejadian Berat Badan Lahir Rendah (BBLR) Studi pada Ibu yang Periksa Hamil ke Tenaga Kesehatan dan Melahirkan di RSUD Banyumas Tahun 2008 [internet]. 2008 [cited 2015 Mei 5] Available from: http://eprints.undip. ac.id/16901/ 